

\title{
A Novel Architecture for Series-Connected Photovoltaic Distributed System with Enhanced Power Quality Using Type-II Fuzzy Controller
}

\author{
Gattagalla Seshadri ${ }^{1 *} \quad$ Gopaluni Venkata Marutheswar ${ }^{2}$ \\ ${ }^{1}$ Siddharth Institute of Engineering and Technology, India \\ ${ }^{2} S$.V. University College of Engineering, India \\ * Corresponding author’s Email: seshu.gattagalla@gmail.com
}

\begin{abstract}
In recent trends, emerging use of Renewable Energy Sources (RES) in the electricity grid has produced new provocations for the effectiveness concerning the features of power quality (PQ), effective energy consumption and voltage maintenance. Most probably, PQ problems and modification have appeared as serious tasks and problems facing electrical services and residential/commercial/industrial users. So, in this paper, Photo Voltaic (PV) generator serves as the main source for improving Power Quality features. The control strategy for the PV generator is designed from Type-2 Fuzzy Logic Controller (FLC). Thus, PQ has to turn out to be more and more severe problem with every single passing day. Most of the applications are worked with high uncertainties. Type-2 FLC have the capability to capture the uncertainties about membership functions of fuzzy sets. Also, it is used to handle these type of problems in group decision making process. As a result, Type-2 FLC provides much more and a lot of attention due to tremendous reactive power and harmonic compensation in this system. For the different voltage instability, PV generator is controlled to cancel out of them. The performance measurement of the PV generator with Type-2 FLC for PQ improvement is validated in MATLAB/Simulink, which show the value of Total Harmonic Distortion (THD) is $0.9103 \%$, power factor is unity and injected values for sag/swell gets better results compared to a traditional technique.
\end{abstract}

Keywords: Fuzzy logic controller (FLC), Power quality (PQ), Photo voltaic (PV), Renewable energy sources (RES).

\section{Introduction}

In the past few years, electrical PQ has been a significant and increasing issues because of the propagation of nonlinear loads [1]. Mostly, problems with equipment and voltage harmonics are outcome from current harmonics created by nonlinear loads. Fast progress of nonlinear load applications in electrical systems causes power quality problems of the electrical energy provided to the consumers. These PQ issues cause several adverse impacts like increase in harmonic level, errors in reactive power, incorrect process of relays, etc. $[2,3]$. Recent systems have turned into active distribution systems because of the growing vision of renewable energy. Developing applications of RES like solar, wind and biomass have additionally the difficulty of voltage disturbances and harmonics due to the alternating nature of sources and converters connected with them $[4,5]$. The direct translation of sunlight into electricity with PV generators coupled to distribution grids is a fast developing market worldwide. The PV inverters are the important crossing point between the grid and PV modules. It must be capable of introducing a certain quantity of reactive power into the network as recommended by the global guidelines. [6].

The incorporation of solar PV systems is growing due to numerous benefits such as easy installation, safer process with lesser operating costs, etc. Several researchers have examined the effects of various kinds of techniques to PQ performance of distribution systems. For grid connected PV systems, many PQ problems may occur. By asking a comprehensive solution to tolerate the power quality within adequate limits, predominantly specified the nature of quickly varying power systems [7, 8]. 
With the help of bounded-voltage design approach, the converter's output voltage constantly stops within the specified range, which evade the integrator setup affected by incorrect reactive power settings. Conversely, this process has some restrictions, like convergence speed is very low, tracking result is poor and oscillates continuously [9]. Some of the studies with the outdated control strategies are not appropriate for reactive power applications [10]. As an end result, current gets disturbed and PV inverter injects that current with high total harmonic distortion (THD) into the grid [11]. To conquer the above mentioned problems, Type-2 FLC strategy for PV generators is utilized to enhance the power quality improvements. Because, it has set of fuzzy rules that can contain several models (equations). It is much better because there is no out of control and it depends on mathematical equations. Moreover, it has more number of parameters (types and membership functions modules) to form their control surface. FLC output completely depends on change of output and there is not sudden change. This make them very useful in case of control non-linear cases, where slight change of the manipulated value changes parameters of the plant or even its dynamics. With the help of this controlling technique, the efficiency of the entire system increases. Furthermore, Type-2 FLC controllers easy to implement and understand because of their rule-base values. By using Type- 2 Fuzzy sets to represent the FLC inputs and outputs will result in the reduction of the FLC rule base when compared to using Type-1 Fuzzy sets. This is because the uncertainty represented in the FOU in Type-2 Fuzzy sets allows us to cover the same range as Type-1 Fuzzy sets with a smaller number of labels. Finally, results showed that the extra degrees of freedom produced by the FOU enables a Type- 2 FLC to provide controlled outputs. The next section provides the related recent works based on solar generators with power quality features.

\section{Literature review}

F.D. Franco, T.V. Vu, D. Gonsulin, H. Vahedi, and C.S. Edrington [12] have presented a model predictive control strategy to regulate the converter for that to control the PV power. With the help of this technique to attain high performance gain, limits the over-current situations and stable operation. But, this type of controllers commonly needs high level computers to support such applications and also requires plant tests and post installation results before it is appropriate for working processes.
M. Hasheminamin, V.G. Agelidis, A. Ahmadi, P. Siano, and R. Teodorescu [13] have proposed a single point reactive power control to minimize the voltage level by absorbing the reactive power. The main advantage of this method is robust, economical and well-organized in removing the voltage rise in affected grid. Although this formulated power control technique needs a considerable amount of calculation, it evades lots of calculations and extra switching for all other PV inverters.

S. Patra, N. Kishor, S.R. Mohanty, and P.K. Ray [14] have developed the three phase grids connected system with single and dual stage circuits. By utilizing the space vector pulse width modulation, smoothen the switching sequence to improve the power quality. But switching with single phase load sometimes provides high transients which make the signal with voltage sag/swell. And also such kind of filters is not suitable for specific loads.

Chettibi, N, and A. Mellit, [15] have presented an intelligent based control technique for grid connected hybrid system with solar panel, battery and fuel cells. By virtue of this technique with neuron fuzzy gain tuners to regulate the power flow of this system. This method has the advantage of enhancing power quality, controls reactive power and stabilized the voltage. But in some of the cases, the plant may be too difficult to be displayed.

I. Abadlia, M. Adjabi, and H. Bouzeria [16] have proposed a power control technique based on sliding mode in grid connected hybrid system. This technique has the advantage of making the system as more expandable, flexible, efficient and robust. For this, it achieves higher performance. However, sometimes, this control can cause high frequency oscillations named chattering which may produce energy loss, change in dynamics and system instability.

\section{Problem identification}

From the above mentioned reviewing mechanism, it is distinguished that. PV system had been successfully employed for enhancing the voltage quality of the power system. It was majorly employed as the power source for power quality conditioners such as predictive control method, SVPWM and sliding mode approaches. In all these workings, the resolution of using PV cell as a main source was to decrease the complication in system modelling, avoiding an additional control structure \& inverter topology and developed an energy savings with excellent service. The challenging task of this type of system design was 1) an appropriate 


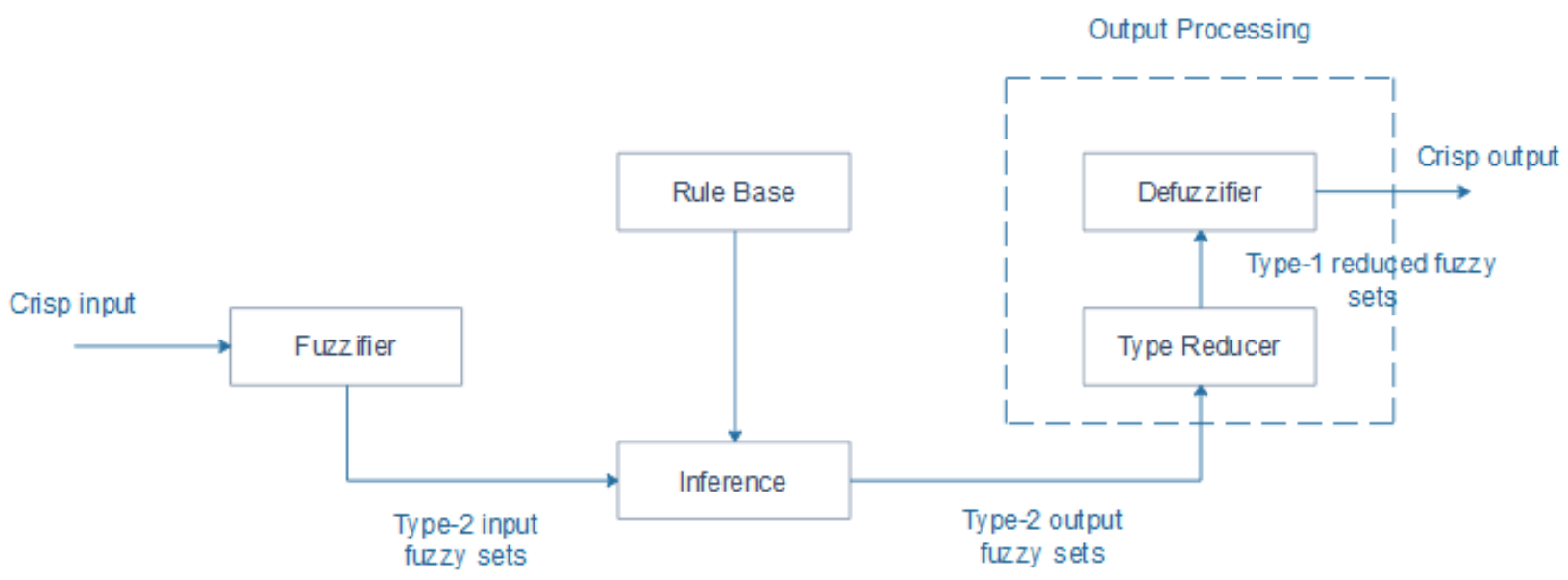

Figure.1 Architecture of Type-2 FLC

topology of PV generator, 2) its control strategy and 3) the entire PV subsystem operation as a power quality conditioner. Regarding this, the scope of the research develops in new instructions; 1) it is potential to progress multilevel topologies for decreasing the total harmonic distortion (THD) of the voltage, 2) soft computing methods for control algorithms of PV generator and 3) new FACTS device theory to minimize the system difficulty. Owing to the declared possibility of new ideas, in this paper, it is determined to develop a gridconnected system with a series connected PV generator. In the below section, the design particulars of the Type-2 FLC for PV cell are presented. As the purpose of this controller is to enhance power quality, it is necessary to comprehend the system. The design of the Type-2 FLC system is presented first. Then, the overall proposed control scheme is described. Finally, the Type-2 FLC structure is illustrated as per power quality requirement.

\section{PV generator with Type-2 FLC control strategy}

\subsection{Proposed Type-2 FLC design}

With the advance development in the Type-2 FLC and their capability to solve the unreliability, utilizing the Type-2 FLC has interacted a lot of improvement in recent trends. Type-2 FLC is an expansion of the method of familiar standard fuzzy sets. The Type-2 fuzzy set is denoted by a membership function (MF) of fuzzy (i.e.) for every element present with membership category is also called a fuzzy set. These sets are 3-dimensional and comprise a foot point of uncertainty (FOU), which is mentioned as new (or) third dimension of fuzzy sets in Type-2 technique.
This type of FLS is mostly used in the FLC, rule based classification, signal processing, etc. and often called as function approximation of fuzzy sets, just because the FLC is modelled to reduce the error function. From the Fig. 1, in Fuzzifier section the inputs are converted into the fuzzy set because numbers are not able to activate the defined rules which is explained in terms of fuzzy sets only. Next these fuzzy sets are calibrated into an output set of fuzzy with the help of inference section. At first, this one is established by measuring every rule using the theory of fuzzy set after that using the mathematical method to determine the output of every rule. Inference make only one rule at a time. From this, output of inference section will be fired rule output with one or more sets. Apparently, the output sets of fired rules have to be transformed into number in the output section. In type reducer section, fuzzy set of type-2 is reduced into fuzzy set of interval value of type-1. Output processing happens after completing the type reducer reduction, yet called as defuzzification. Since, a fuzzy set of type reducer has been always a number of finite intervals, the value of defuzzifier is just the difference between the end points of two intervals. The architecture of Type-2 FLC has 2 outputs, one is numerical crisp values and another one is type reduced values.

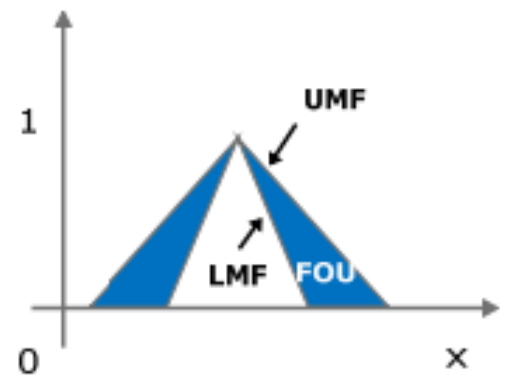

Figure.2 Membership function of Type-2 FLC 


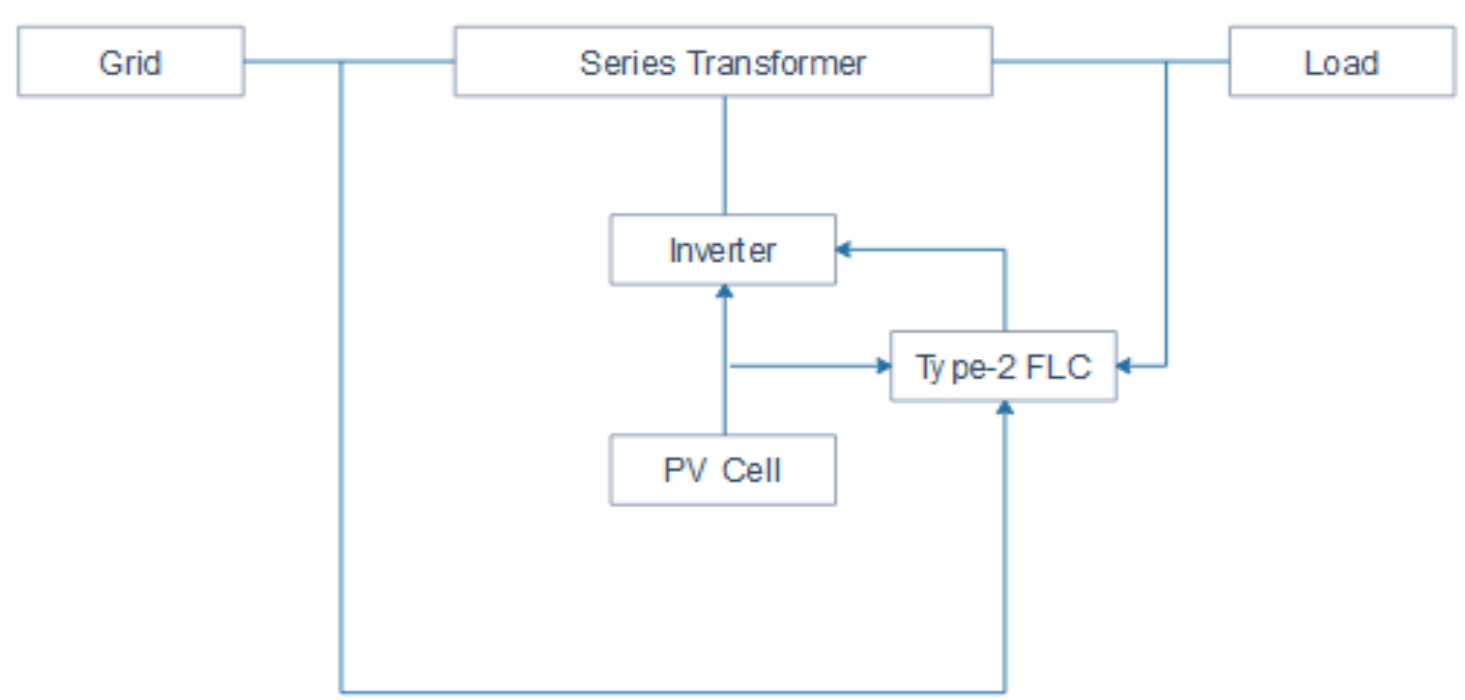

Figure.3 The block diagram of system under study for PQ enhancement by PV cell.

In Fig. 2, the design process of Type-2 FLC, it has 2-input, 1-ouput and each variable for input/output has 7 linguistic variables. Even though, by using the Type-2 FLC which terminates the FOU, upper membership function (UMF) and lower membership function (LMF) to provide firing strengths. The area between the UMF and LMF is defined as FOU. It produces a further degree of freedom that create it feasible to solve uncertainty. Although in real world environments, the fuzzy sets of Type-2 FLC have the ability to produce a relevant framework to solve the uncertainty. In the proposed work, four inputs are given to Type-2 FLC to attain the control signal for inverter of the PV cell.

In Type-2 FLC, the fuzzy set in $\mathrm{X}$ is $\tilde{A}$ and the membership grade is $\mu_{A}(x, u)$

$$
\tilde{A}=\left\{\left((x, u), \mu_{\hat{A}}(x, u)\right) \mid \forall x \in X\right\}
$$

$\tilde{A}$ Can also be expressed as

$$
\tilde{A}=\iint \mu_{A}(x, u) /(x, u)
$$

Where $J_{x} \subseteq[0,1]$

Where $\iint()$ denote union over all admissible $x$ and $u$. For discrete universe of discourse $\Phi$ is replaced by $\sum . \tilde{A}$ can be re-expressed as

$$
\tilde{A}=\{(x, \mu(x)) \mid \forall \in X\}
$$

$$
\tilde{A}=\int\left[\int f_{x}(u) / u\right] / x, J_{x} \subseteq[0,1]
$$

If $X$ and $J_{x}$ are both discrete then

$$
\tilde{A}=\sum_{i=1}^{N}\left[\sum f_{x_{i}}(u) / u\right] x_{i}
$$

Uncertainty in the primary membership of a type-2 fuzzy set, $\tilde{A}$ consists of bounded region that we call the FOU. It is the union of all primary membership [19], that is,

$$
\operatorname{FOU}(\tilde{A})=U_{x \in X} J_{x}
$$

In Fig. 3, the block diagram for PV generator based Type-2 FLC is shown. In this, the grid is connected to the load through a series transformer, which is used to minimize the voltage problems. That transformer is coupled with PV cell through an inverter. The determination of that transformer associated to PV cells is that, to transfer the power with requisite voltage and angle for regulating source voltage instabilities. The voltage quality can be evaluated by means of its voltage sag and swell deviation from load reference value. If the output voltage deviation is less, the output voltage quality is extraordinary. Otherwise, Type-2 FLC is designed to rectify the voltage quality problems regardless of the supply voltage distortion. Meanwhile, it is observed that, for the Type-2 FLC strategy, certain system constraints are specified to deliver an adaptive control signal for the inverter. 


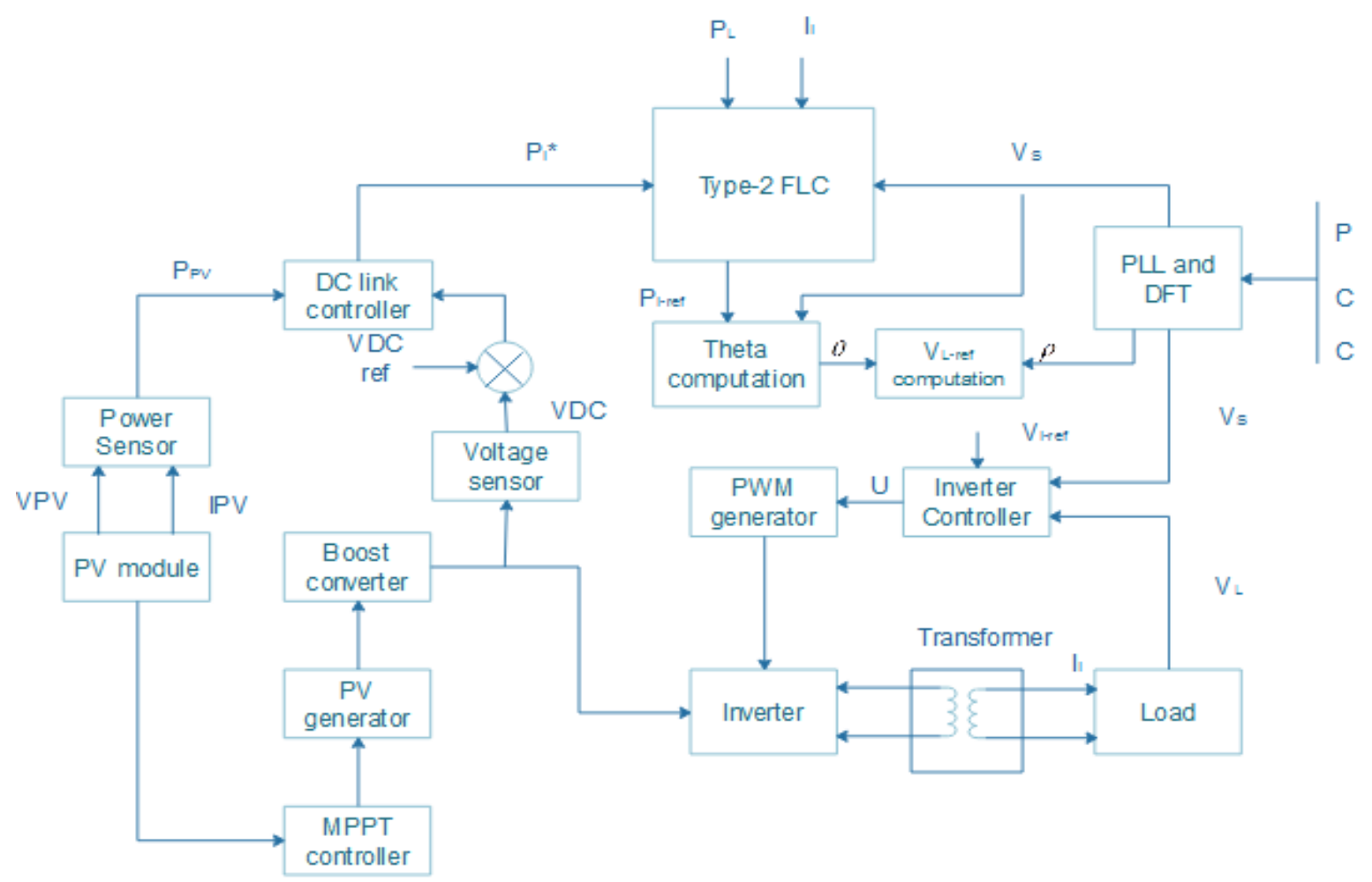

Figure.4 Overall control strategy with Type-2 FLC design

The overall control strategy with Type-2 FLC design is shown in Fig. 4. This structure is extended with four input values and one output value. The four inputs are ( $P_{L}$ (load power), $V_{S}$ (source voltage), $I_{i^{*}}$ (injected current) and $P_{i^{*}}(\mathrm{PV}$ injection power)) and output is $P_{\text {iref }}$ (injective power reference). From that, once the inputs and output of the Type-2 FLC is trained, it will be used to produce $P_{\text {iref }}$ to control signal PWM generator to the inverter of PV cell. The mathematical demonstration of the above mentioned points is written as follows.

Let the source voltage and load voltage are expressed as:

$$
\begin{aligned}
& \overline{V_{S}}(t)=V_{s}<\rho(t) \\
& \overline{V_{L}}(t)=V_{L}<\theta(t)
\end{aligned}
$$

Where, $\overline{V_{S}}(t)$ and $\overline{V_{L}}(t)$ are the vector representation of source and load voltages correspondingly at time t. $V_{S}(t)$ and $V_{L}(t)$ are magnitudes of source and load voltage respectively at time t. $\rho(t)$ and $\theta(t)$ are the phase angle of source and load voltages at time t. Now, the magnitude of load voltage must be equal at all periods to preserve the load away from destruction regardless of distortion in source voltage. In spite of maintaining the reference voltage, suitable control signals given to PWM generator. If there is some trouble in voltage source, at first it is declared by
Type-2 FLC, because it is one of the inputs for controlling. The source voltage magnitude and angle are calculated through a PLL and given to controller. The generation of appropriate control signals to PWM generator are described as follows.

\subsubsection{Boost converter control}

Boost converter process held in between the inverter and PV cell. The determination of this converter is to improve the PV output voltage to a definite level to withstand the voltage for power reversal determination through an inverter. The collected DC from PV section is kept in a capacitor with a constant voltage. In spite of producing extra energy from $\mathrm{PV}$, this converter is measured from a Maximum Power Point Tracking (MPPT) method. At this time, the incremental conductance process is used for MPPT purpose.

\subsubsection{DC link voltage control}

For controlling the inverter process, DC-link voltage is considered as key parameter. In order to maintain the DC-link as constant, then it will be matched with its reference value and forwarded to the controller to decide proper control signal. This signal is the sign of change in PV cell output, which will be supplementary added to actual PV power. This process controls the inverter section. It is denoted as follows. 
The error between DC-link voltage and its reference are written as;

$$
V_{D C-r e f}-V_{D C}(t)=e_{D C}(t)
$$

Where, $V_{D C}(t)$ is voltage of DC-link, $e_{D C}(t)$ is error value and $V_{D C-r e f}$ is reference dc-link voltage with time t.

Depends on the error, actual output power injection of PV into the grid is calculated as follows,

$$
P_{i^{*}}(\mathrm{t})=P_{P V}(\mathrm{t})+K_{P 1^{*}} e_{D C}(\mathrm{t})+K_{i 1} \int e_{D C}(t)
$$

Where, $P_{i^{*}}(\mathrm{t})$ is the reference value, $P_{P V}(\mathrm{t})$ is output of PV cell. $K_{P 1^{*}}$ and $K_{i 1}$ are proportional and integral gains of the controller. The output of this section is fed to Type-2 FLC for further development in inverter process.

\subsubsection{Inverter controller}

Inverter section generates a controlled signal for PWM generator from PV cell. At that time, it checks both source and load voltage magnitudes to produce the proper PWM signals. The mathematical illustration of the inverter section is written as follows;

$$
\begin{gathered}
u(t)=\left[V_{L-r e f}(t)-V_{S}(t)\right]+K_{p 2^{*}}\left[V_{L-r e f}(t)-\right. \\
\left.V_{L}(t)\right]
\end{gathered}
$$

Where, $u(t)$ is the controlled output signal which is provide for PWM generator, $K_{p 2^{*}}$ is the proportional gain of the inverter and $V_{L-r e f}(t)$ is the reference load voltage magnitude. It is described as follows.

$$
V_{L-r e f}(\mathrm{t})=\sqrt{2} V_{L^{*}}[\sin (\rho(t)+\theta(t))]
$$

$$
\begin{aligned}
& \text { Where } \\
& \quad \theta(t)=-\cos \left(\frac{V_{L}(t)\left(P_{L}-P_{i-r e f(t)}\right)}{S_{L} V_{S}(t)}+\right. \\
& \left.\frac{R_{S} S_{L}}{V_{L}(t) V_{S}(t)}\right)+\varphi(t)
\end{aligned}
$$

$V_{L}$ is the constant load voltage requisite by the load, $\varphi(t)$ is the argument of injected current, $R_{S}$ is the resistance of source impedance, $P_{L}$ and $S_{L}$ are the active and VA power of load. $P_{i-r e f}(t)$ is the output power injection of PV into the grid.

The most important responsibility of calculating control signal for PWM generator is written in equation 10 and 11. This is appropriate for all voltage instabilities. The voltage distortion is decided by Type-2 FLC through its one of the inputs and adjust to its modifications by varying reference power injection for equation 11. As a result of deviations in source voltage and reference of PV injection power, hence provide better results for voltage quality and explained in the next section.

\section{Simulation results and discussions}

In this segment, the performance of the Type-2 FLC controller for enhancing the power quality is investigated. Type-2 FLC handles both balanced and unbalanced situations without any difficulties and injects the appropriate voltage component to correct rapidly any variance in the supply voltage to keep the load voltage balanced and constant at the nominal value. As compared with conventional controllers, Type-2 FLC has low steady state errors and low settling time. In this paper, four inputs and single output fuzzy inference system are considered. The input for the fuzzy system is represented as error of PI controller. The fuzzy rules are obtained with if-then statements. The given fuzzy inference system is a combination of four input and single output. This input is related with the logical operator AND/OR operators. AND logic gives the output as the minimum value of the input and OR logic produces the output as the maximum value of the input. This process is evaluated while the source voltage becomes sag/swells. In order to confirm the above mentioned work, a modest single phase system is established and verified for different voltage sag/swell disorders. To authenticate the performance of Type-2 FLC, it is analysed with two cases and compared with traditional controller techniques [17, 18]. From the paper [17, 18], power quality features are improved with the help of PI controller and ANFIS (Adaptive Neuro Fuzzy Inference System) controller. The results from those papers are compared with the proposed technique in the below mentioned comparison table 1 .

\section{Case 1: System performances during voltage sag}

In this case, voltage sag of $60 \%$ is applied in supply voltage to check the conventional and proposed systems performances. The illustration of system performance for the above case is presented in Fig. 5. 


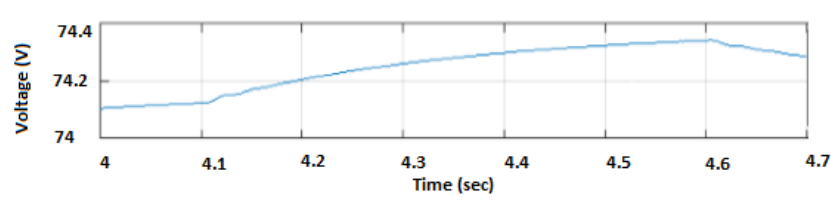

(a)

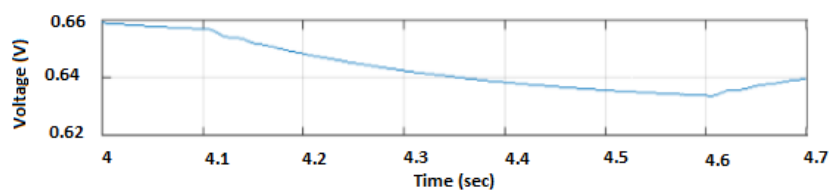

(b)

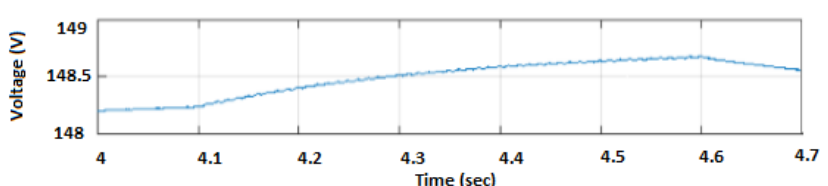

(c)

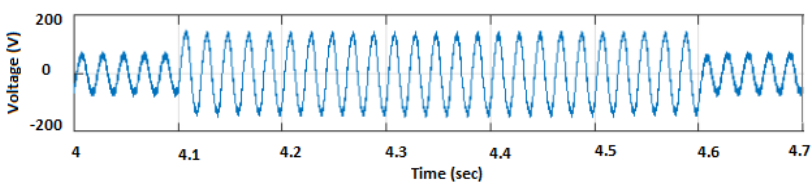

(d)

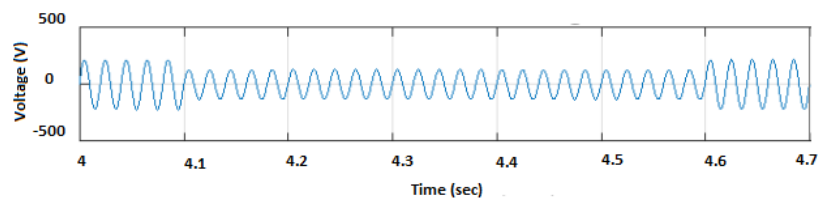

(e)

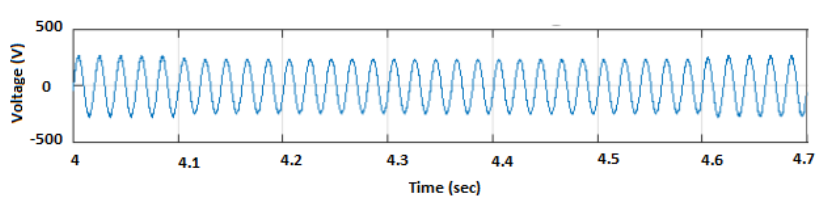

(f)

ANFIS controller

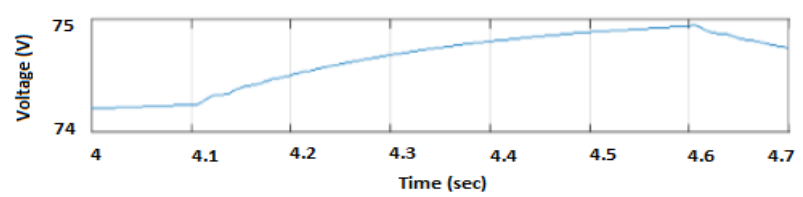

(a)

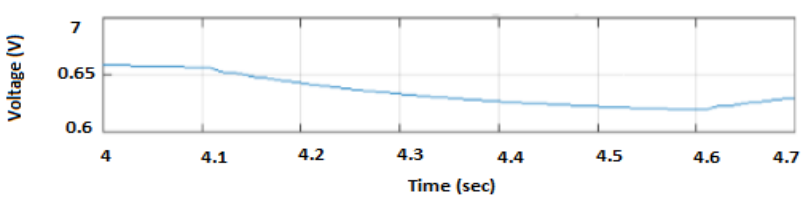

(b)

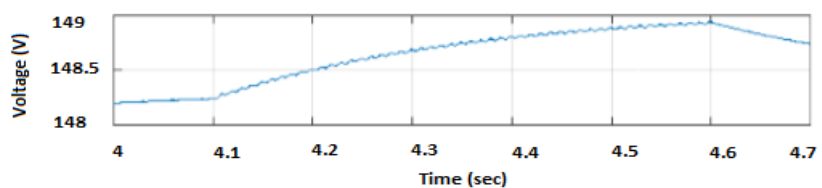

(c)

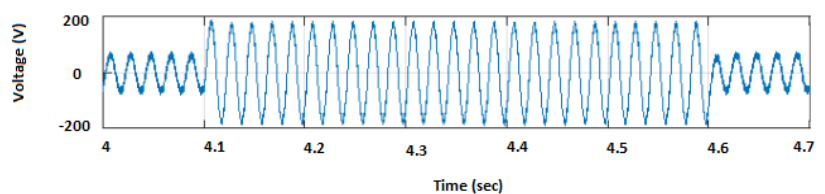

(d)

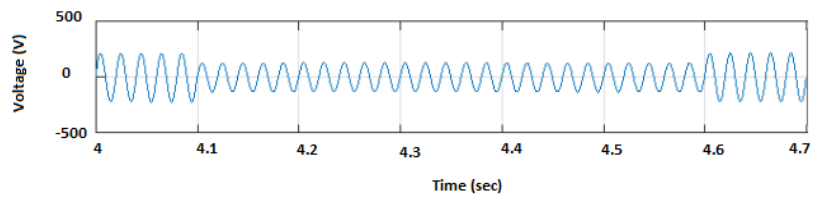

(e)

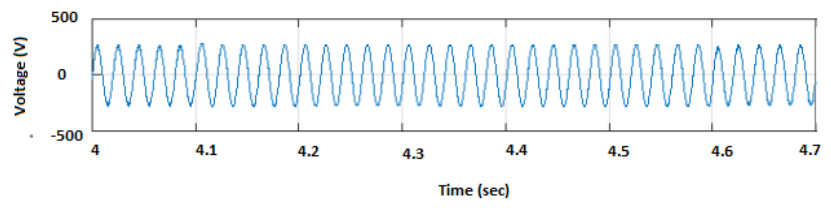

(f)

Figure.5 The performance of conventional and proposed systems in $60 \%$ sag: PV voltage output (b) PV current output (c) Dc link Voltage (d) Transformer voltage (e) Source voltage (f) Load voltage

From above Fig. 5, it is notable that, sag in supply voltage is inserted during $4.1 \mathrm{~S}$ to $4.6 \mathrm{~S}$.

Here, during sag time, PV output voltage and DC voltage are increasing ramp way for both conventional and proposed systems where current is decreasing and in opposite way after sag. Since no longer supply voltage support the load, injected voltage from the transformer is supporting. It is visible for both conventional and proposed systems. Supply voltage is also shown. Finally, in conventional PI controlled system, load voltage had tried to reach the reference of supply voltage and little bit lower than the supply voltage where as in
Type-2 FLC system and it had reached the reference. It is due to the superior control capability of Type-2 FLC. Now the performance is analyzed in swell operation.

\section{Case 2: System performances during voltage swell}

In this case, voltage swell of $125 \%$ is applied in supply voltage to check the conventional and proposed systems performances. The illustration of system performance for the above case is presented in Fig. 6. 




(a)

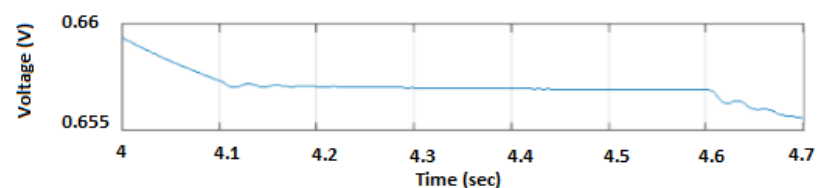

(b)

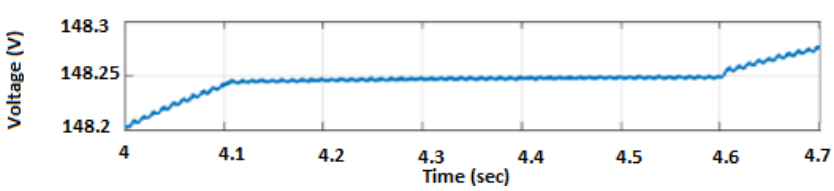

(c)

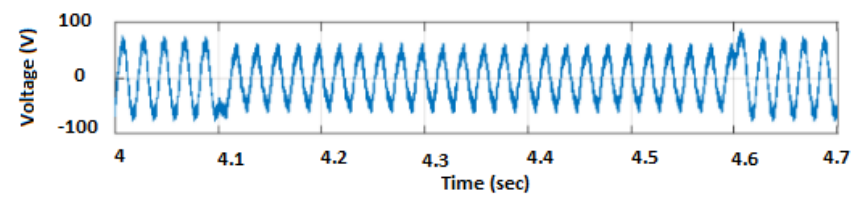

(d)



(e)

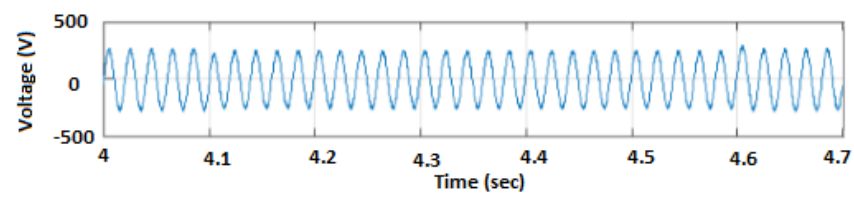

(f)

ANFIS controller

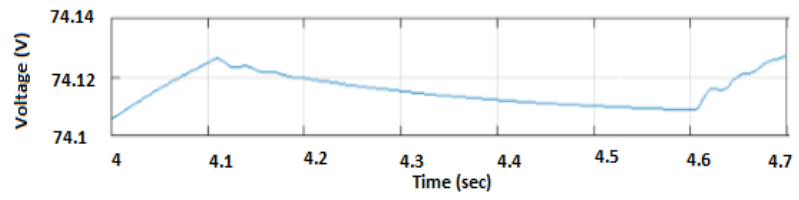

(a)



(b)

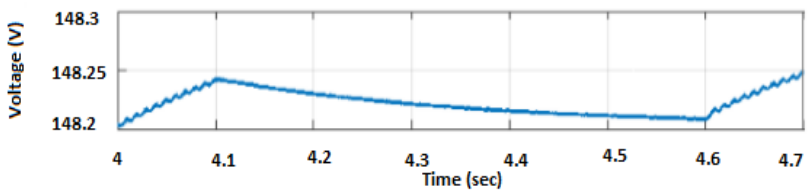

(c)

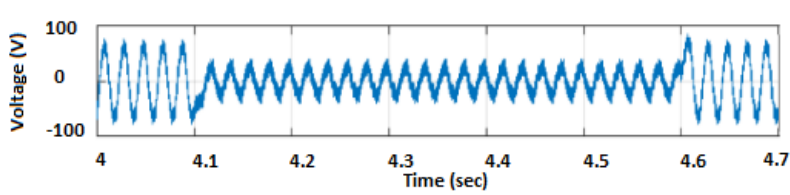

(d)

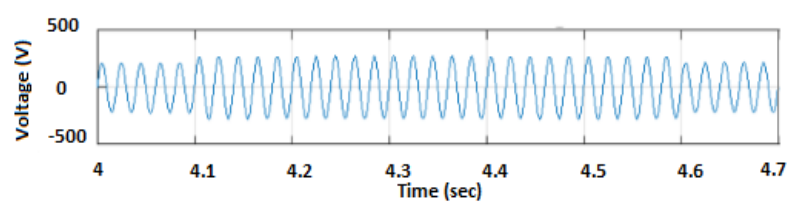

(e)



(f)

Type-2 FLC

Figure.6 The performance of conventional and proposed systems in 125\% swell: PV voltage output (b) PV current output (c) Dc link Voltage (d) Transformer voltage (e) Source voltage (f) Load voltage

From above Fig. 6, it is notable that, $125 \%$ of swell is applied to supply voltage during $4.1 \mathrm{~S}$ to 4.6S. Here, during swell time, opposite to as a case in sag time; PV output voltage, current and DC voltages work in opposite way can be visible in Fig. 6 . Injected voltage from the transformer is reduced to cancel out the swell supply voltage. The difference in its phase with supply voltage results in good load voltage. It is visible for both conventional and proposed systems. Supply voltage with swell is also shown. Finally, in conventional PI controlled system, load voltage had tried to reach the reference of supply voltage and little bit lower than the supply voltage where as in Type-2 FLC system and it had reached the reference. It is due to the superior control capability of Type-2 FLC. The in-depth view of sag and swell operations in conventional and proposed systems presented in Fig. 7. It is shown as follows. 


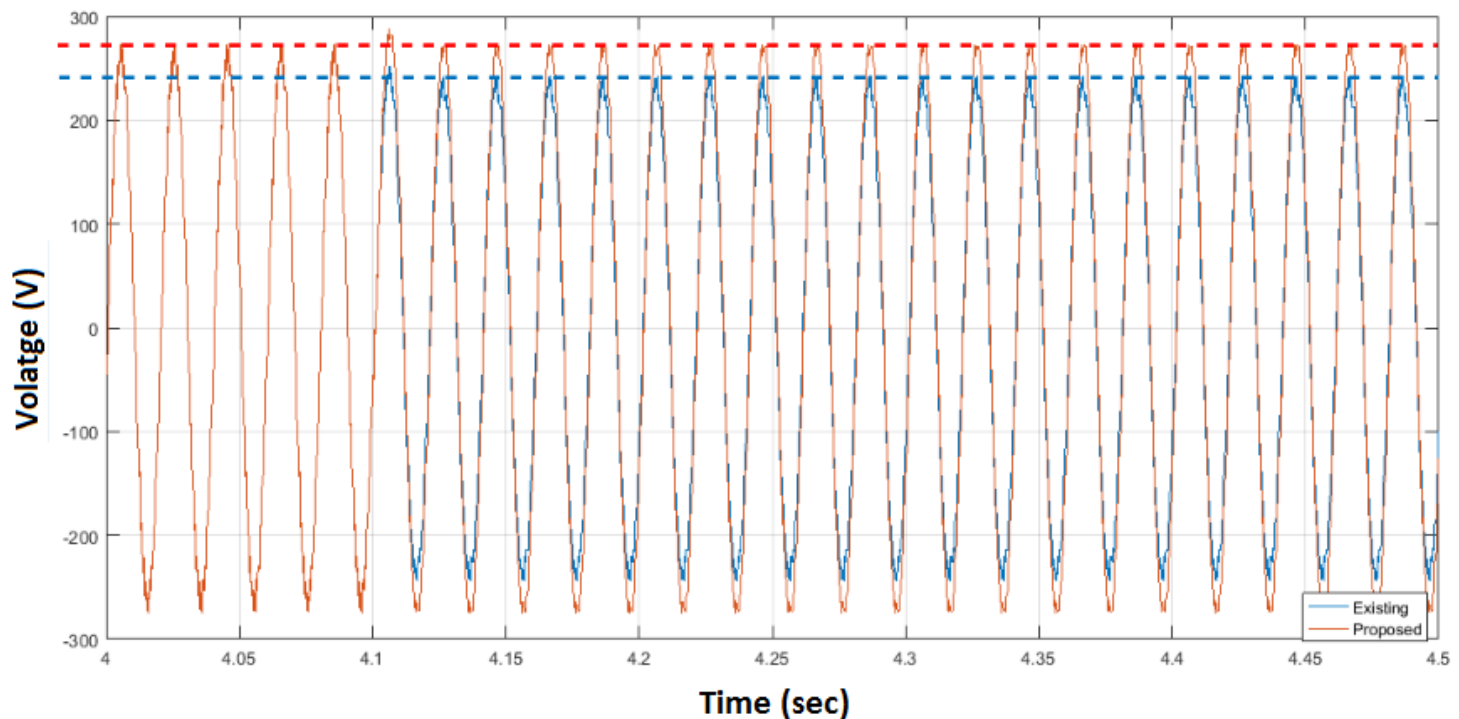

(a)

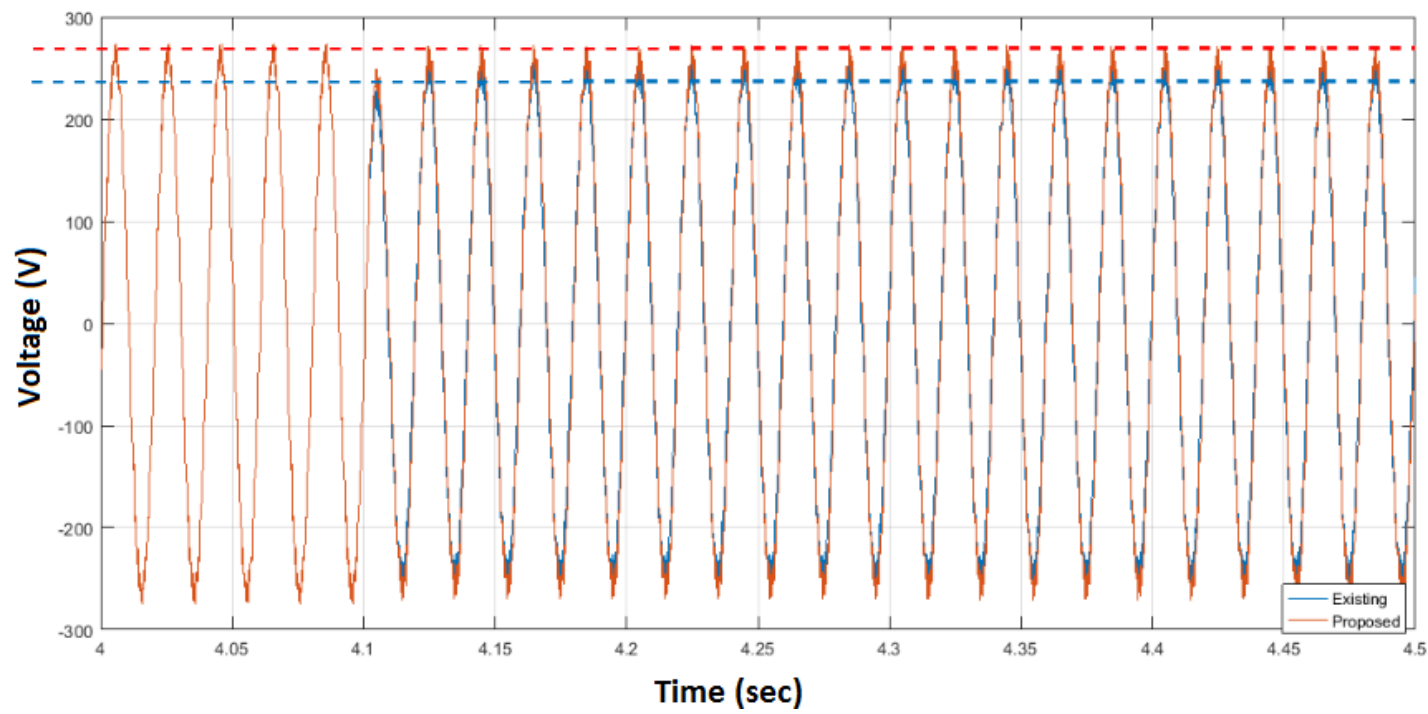

(b)

Figure.7 The performance of existing and proposed system during sag and swell: Load voltage during sag (b) Load voltage during swell

Table 1. Comparison table for Type-2 FLC with existing

\begin{tabular}{|c|c|c|c|}
\hline Parameter & $\begin{array}{c}\text { PI } \\
\text { controller } \\
{[\mathbf{1 7 ]}}\end{array}$ & $\begin{array}{c}\text { Anfis } \\
\text { controller } \\
{[\mathbf{1 8}]}\end{array}$ & $\begin{array}{c}\text { Type-2 } \\
\text { FLC }\end{array}$ \\
\hline $\begin{array}{c}\text { PV output } \\
\text { Current }\end{array}$ & 3.4 & 0.63 & 0.4 \\
\hline $\begin{array}{c}\text { PV output } \\
\text { voltage }\end{array}$ & 45 & 74.3 & 78 \\
\hline $\begin{array}{c}\text { Injected } \\
\text { transformer } \\
\text { voltage (sag) }\end{array}$ & $150 \mathrm{v}$ & $180 \mathrm{v}$ & $200 \mathrm{v}$ \\
\hline $\begin{array}{c}\text { Injected } \\
\text { transformer } \\
\text { voltage } \\
\text { (swell) }\end{array}$ & $100 \mathrm{v}$ & $80 \mathrm{v}$ & $40 \mathrm{v}$ \\
\hline $\begin{array}{c}\text { Power factor } \\
\text { lagging }\end{array}$ & 1 (unity) & 1 (unity) \\
\hline THD & $4 \%$ & $1.872 \%$ & $0.9103 \%$ \\
\hline
\end{tabular}

From the above discussions, it shows that, proposed Type-2 FLC is much better control strategy than a traditional controller for enhancing power quality during voltage sag/swell.

Table 1 shows the performance measurements of Type-2 FLC with traditional techniques. The above table displays Type-2 FLC achieves better results when compared with other conventional techniques. Below, Fig. 8 shows the comparison graph for Type2 FLC with other existing works.

\section{Conclusion}

In this paper, Type-2 FLC is employed in terms of emerging a control scheme to enhance the power quality features, when RES interfaced with grid. Here, PV cells are used as the main source to 


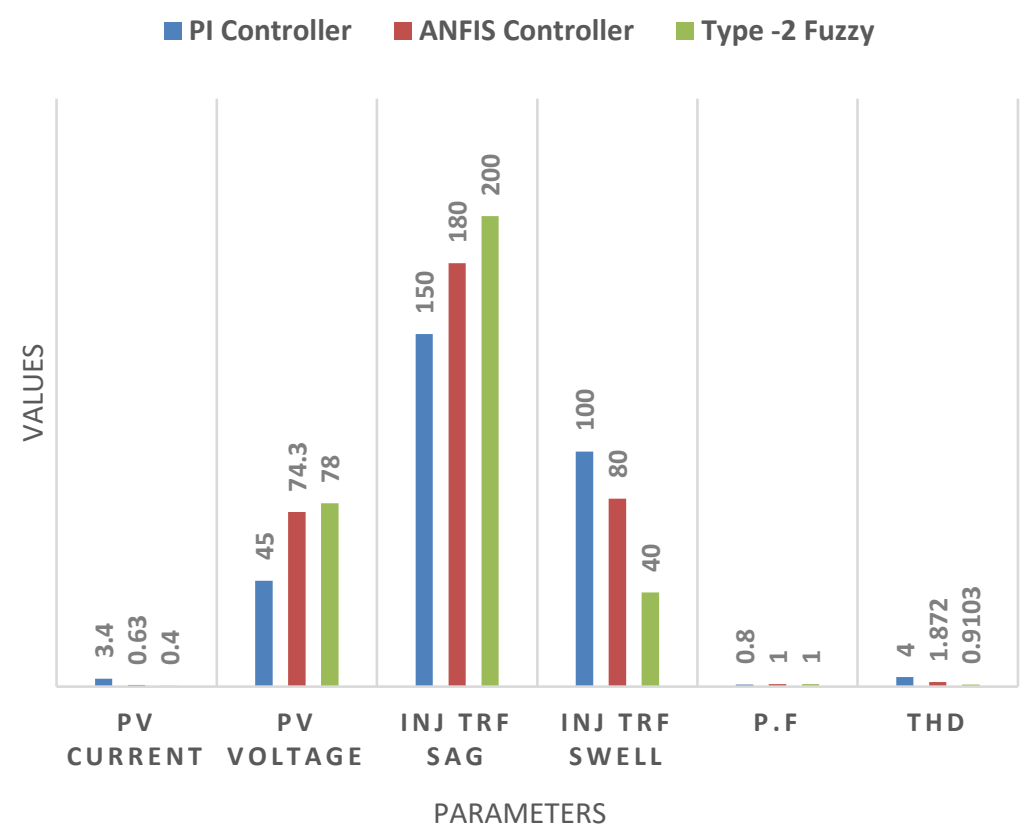

Figure.8 Comparison graph for Type-2 FLC with existing works

minimize the voltage sag/swell. The performance measurement of the Type-2 FLC is verified from $60 \%$ sag and $125 \%$ swell operation and proved to be much better results when compared with conventional controllers. The PV based approach is found to be well-organized and it provides strong power quality enhancement in power distribution systems. The characteristic structures of PV output voltage, current, transformer injected voltage, DC voltage and supply/load voltages are also exposed for the period of sag and swell operations. The results of simulation presented and discussed in this paper are total harmonic distortion (THD) of voltage at the PCC, supply current, and load voltage. It is observed that the load voltage THD reduced to the level of $0.9103 \%$. The THD and the amount of unbalance in load voltage decreased by the application of Type-2 FLC. It performed better than the traditional methods in mitigating harmonics and voltage sag/swell. This work can be extended for different types of load and THD can be minimized. Recent optimization techniques may be used to find optimal solutions; their performances may be compared.

\section{References}

[1] A.R. Reisi, M.H. Moradi, and H. Showkati, "Combined photovoltaic and unified power quality controller to improve power quality", Solar Energy, Vol.88, pp. 154-162, 2013.

[2] S. Seme, N. Lukač, B. Štumberger, and M. Hadžiselimović, "Power quality experimental analysis of grid-connected photovoltaic systems in urban distribution networks", Energy, Vol.139, pp.1261-1266, 2017.

[3] Z. Ahmad and S. N. Singh, "An improved single phase transformerless inverter topology for grid connected PV system with reduce leakage current and reactive power capability", Solar Energy, Vol.157, pp.133-146, 2017.

[4] D. Divyalakshmi, and N.P. Subramaniam, "Photovoltaic based DVR with Power Quality Detection using Wavelet Transform", Energy Procedia, Vol.117, pp.458-465, 2017.

[5] W.U. Tareen, S. Mekhilef, M. Seyedmahmoudian, and B. Horan, "Active power filter (APF) for mitigation of power quality issues in grid integration of wind and photovoltaic energy conversion system", Renewable and Sustainable Energy Reviews, Vol.70, pp.635-655, 2017.

[6] W.J. Praiselin and J.B. Edward, "Voltage Profile Improvement of Solar PV Grid-Connected Inverter with Micro Grid Operation using PI Controller", Energy Procedia, Vol.117, pp.104111, 2017.

[7] T.K. Roy and M.A. Mahmud, "Active power control of three-phase grid-connected solar PV systems using a robust nonlinear adaptive backstepping approach", Solar Energy, Vol.153, pp.64-76, 2017.

[8] G.S. Elbasuony, S.H.A. Aleem, A.M. Ibrahim, and A.M. Sharaf, "A unified index for power quality evaluation in distributed generation systems”, Energy, Vol.149, pp.607-622, 2018. 
[9] Y. Wang, B. Ren, and Q.C. Zhong, "Boundedvoltage Power Flow Control for Grid-tied PV Systems", IFAC-PapersOnLine, Vol.50, No.1, pp.7699-7704, 2018.

[10] Z. Ahmad and S.N. Singh, "Improved modulation strategy for single phase grid connected transformerless PV inverter topologies with reactive power generation capability", Solar Energy, Vol.163, pp.356-375, 2018.

[11] L. Collins and J.K. Ward, "Real and reactive power control of distributed PV inverters for overvoltage prevention and increased renewable generation hosting capacity", Renewable Energy, Vol.81, pp.464-471, 2015.

[12] F.D. Franco, T.V. Vu, D. Gonsulin, H. Vahedi, and C.S. Edrington, "Enhanced performance of PV power control using model predictive control", Solar Energy, Vol.158, pp.679-686, 2017.

[13] M. Hasheminamin, V.G. Agelidis, A. Ahmadi, P. Siano, and R. Teodorescu, "Single-point reactive power control method on voltage rise mitigation in residential networks with high PV penetration", Renewable Energy, Vol.119, pp.504-512, 2018.

[14] S. Patra, N. Kishor, S.R. Mohanty, and P.K. Ray, "Power quality assessment in 3- $\Phi$ grid connected PV system with single and dual stage circuits", International Journal of Electrical Power \& Energy Systems, Vol.75, pp.275-288, 2016.

[15] N. Chettibi and A. Mellit, "Intelligent control strategy for a grid connected PV/SOFC/BESS energy generation system", Energy, Vol.147, pp.239-262, 2108.

[16] I. Abadlia, M. Adjabi, and H. Bouzeria, "Sliding mode based power control of gridconnected photovoltaic-hydrogen hybrid system”, International Journal of Hydrogen Energy, Vol.42, No.47, pp.28171-28182, 2017.

[17] N. Saadat, S.S. Choi, and D.M. Vilathgamuwa, "A series-connected photovoltaic distributed generator capable of enhancing power quality", IEEE Transactions on Energy Conversion, Vol.28, No.4, pp.1026-1035, 2013.

[18] G. Manusha and M. Srikanth, "Performance Factors of Grid Interconnected PV System using ANFIS Controller", Indian Journal of Science and Technology, Vol.9, No.36, 2016. 